\title{
4,6- $\alpha$-Glucanotransferase activity occurs more widespread in Lactobacillus strains and constitutes a separate GH70 subfamily
}

\author{
Hans Leemhuis • Willem P. Dijkman • \\ Justyna M. Dobruchowska • Tjaard Pijning • \\ Pieter Grijpstra • Slavko Kralj • \\ Johannis P. Kamerling • Lubbert Dijkhuizen
}

Received: 23 December 2011 /Revised: 3 February 2012 / Accepted: 3 February 2012 / Published online: 25 February 2012

(C) The Author(s) 2012. This article is published with open access at Springerlink.com

\begin{abstract}
Family 70 glycoside hydrolase glucansucrase enzymes exclusively occur in lactic acid bacteria and synthesize a wide range of $\alpha$-D-glucan (abbreviated as $\alpha$ glucan) oligo- and polysaccharides. Of the 47 characterized GH70 enzymes, 46 use sucrose as glucose donor. A single GH70 enzyme was recently found to be inactive with sucrose and to utilize maltooligosaccharides $[(1 \rightarrow 4)-\alpha$-D-glucooligosaccharides] as glucose donor substrates for $\alpha$ glucan synthesis, acting as a 4,6- $\alpha$-glucanotransferase $(4,6-\alpha \mathrm{GT})$ enzyme. Here, we report the characterization of
\end{abstract}

Electronic supplementary material The online version of this article (doi:10.1007/s00253-012-3943-1) contains supplementary material, which is available to authorized users.

H. Leemhuis · W. P. Dijkman · J. M. Dobruchowska

P. Grijpstra $\cdot$ S. Kralj · J. P. Kamerling $•$ L. Dijkhuizen $(\bowtie)$

Microbial Physiology, Groningen Biomolecular Sciences and

Biotechnology Institute (GBB), University of Groningen,

Nijenborgh 7 ,

9747 AG, Groningen, The Netherlands

e-mail: 1.dijkhuizen@rug.nl

T. Pijning

Biophysical Chemistry, Groningen Biomolecular Sciences and

Biotechnology Institute (GBB), University of Groningen,

Nijenborgh 7,

9747 AG, Groningen, The Netherlands

H. Leemhuis $\cdot$ L. Dijkhuizen

Carbohydrate Competence Center (CCC),

Nijenborgh 7,

9747 AG, Groningen, The Netherlands

Present Address:

S. Kralj

Genencor,

Archimedesweg 30,

2333 CN, Leiden, The Netherlands two further GH70 4,6- $\alpha$ GT enzymes, i.e., from Lactobacillus reuteri strains DSM 20016 and ML1, which use maltooligosaccharides as glucose donor. Both enzymes cleave $\alpha 1 \rightarrow 4$ glycosidic linkages and add the released glucose moieties one by one to the non-reducing end of growing linear $\alpha$-glucan chains via $\alpha 1 \rightarrow 6$ glycosidic linkages $(\alpha 1 \rightarrow 4$ to $\alpha 1 \rightarrow 6$ transfer activity). In this way, they convert pure maltooligosaccharide substrates into linear $\alpha$-glucan product mixtures with about $50 \% \alpha 1 \rightarrow 6$ glycosidic bonds (isomalto/maltooligosaccharides). These new $\alpha$-glucan products may provide an exciting type of carbohydrate for the food industry. The results show that $4,6-\alpha \mathrm{GTs}$ occur more widespread in family GH70 and can be considered as a GH70 subfamily. Sequence analysis allowed identification of amino acid residues in acceptor substrate binding subsites +1 and +2 , differing between GH70 GTF and 4,6$\alpha \mathrm{GT}$ enzymes.

Keywords $\alpha$-Glucan · Fiber · Glucansucrase · Glycoside hydrolase $\cdot 4,6$ - $\alpha$-Glucanotransferase .

Isomaltooligosaccharide $\cdot$ Starch

\section{Introduction}

The glycoside hydrolase (GH) family 70 (Cantarel et al. 2009) is a group of extracellular bacterial glucansucrase (GTF) enzymes that synthesize $\alpha$-D-glucan (abbreviated as $\alpha$-glucan) polymers such as dextran, mutan, alternan, and reuteran (Côté and Robyt 1982; Monchois et al. 1999; van Hijum et al. 2006; Moulis et al. 2006; Schwab et al. 2007). These polymers form a protective layer around the cell (Kaditzky et al. 2008; Walter et al. 2008). In theory, four 
types of $\alpha$-glycosidic bonds can be formed between Dglucopyranose residues (at C-2, C-3, C-4, and C-6), and all four product specificities have been found among the different GH70 enzymes (Fabre et al. 2005; van Hijum et al. 2006). The GH70 enzymes from lactobacilli typically form products with two types of $\alpha$-glycosidic linkages and synthesize branches, resulting in complex $\alpha$-glucan structures. It was generally accepted that all GH70 enzymes use sucrose as glucose donor, but recently, we reported that Lactobacillus reuteri 121 encodes a GH70 enzyme, called 4,6$\alpha$-glucanotransferase (4,6- $\alpha$ GT-B), that uses maltooligosaccharides $(\alpha 1 \rightarrow 4$-linked glucose residues), instead of sucrose, as glucose donor to synthesize linear isomalto/ maltooligosaccharide product mixtures with up to $33 \%$ isomalto-sequences ( $\alpha 1 \rightarrow 6$-linked glucose residues) (Kralj et al. 2011; Dobruchowska et al. 2012). In addition, dextrin dextrinases (EC 2.4.1.2) form isomalto/maltooligosaccharides; however, these products contain branches (Naessens et al. 2005), whereas the 4,6- $\alpha$ GT-B products are linear (Dobruchowska et al. 2012). Although the physiological function of this 4,6- $\alpha$ GT-B enzyme is still unknown, it is interesting to note that this $L$. reuteri 121 also contains a standard type of GH70 enzyme (GTF-A), which synthesizes reuteran (a branched glucan with $\alpha 1 \rightarrow 4$ and $\alpha 1 \rightarrow 6$ linkages) from sucrose (Kralj et al. 2002; van Leeuwen et al. 2008a). The observation that the recombinant GTF-A enzyme makes an $\alpha$-glucan polymer indistinguishable from the $\alpha$-glucan polymer isolated from $L$. reuteri 121 supernatant implies that 4,6- $\alpha$ GT-B has no essential role in the synthesis of the extracellular $\alpha$-glucan under the conditions tested, e.g., rich media with sucrose.

Today (November 2011), 135 GH70 sequences are reported in the CAZy database (Cantarel et al. 2009), of which 47 have been experimentally characterized (http:// www.cazy.org). Three-dimensional structures have been reported for the N-terminally truncated GTF-180 enzyme of $L$. reuteri 180 (Vujičić-Žagar et al. 2010), which makes a branched glucan consisting of $\alpha 1 \rightarrow 6$ and $\alpha 1 \rightarrow 3$ glycosidic bonds (Kralj et al. 2004a; van Leeuwen et al. 2009), the Nand C-terminally truncated mutan $[(1 \rightarrow 3)-\alpha$-glucan with about $10 \% \quad \alpha 1 \rightarrow 6$ glycosidic bonds] synthesizer GTF-SI of Streptococcus mutans (Ito et al. 2011) and DSR-E of Leuconostoc mesenteroides NRRL B1299, which attaches glucose moieties on dextran via $\alpha 1 \rightarrow 2$ glycosidic bonds (e.g., branches) (Brison et al. 2012). The catalytic domain of these enzymes has a $(\beta / \alpha)_{8}$-fold, which is circularly permutated compared to the arrangement of the catalytic domain in the evolutionary related enzymes of the GH13 and GH77 families. Note that also the GH13 amylosucrase enzymes synthesize $\alpha$-glucans from sucrose (Potocki de Montalk et al. 2000), though only linear $(1 \rightarrow 4)$ - $\alpha$-glucans, whereas all other GH13 enzymes either hydrolyze or disproportionate $\alpha$-glycosidic bonds between two glucose moieties (Stam et al. 2006; Kelly et al. 2009b). In the GH70 family, as well as in the GH13 and GH77 families, the catalytic nucleophile (Asp1025; numbered according to GTF-180), acid/base (Glu1063), and transition state stabilizer (D1136) are located at the C-terminal ends of the $\beta$ strands, as revealed by a sucrose bound structure of GTF180 (Vujičić-Žagar et al. 2010). Despite the availability of crystal structures and the observation that mutations near the active site can alter the ratio of $\alpha$-glycosidic bonds synthesized (Hellmuth et al. 2008), the reaction specificity of GH70 is not well understood, limiting the design of GH70 variants capable of synthesizing predefined $\alpha$-glucan polymers.

Here, we describe the cloning, expression, and characterization of the second and third GH70 enzyme inactive with sucrose as donor substrate. The two GH70 genes of $L$. reuteri DSM20016 and L. reuteri ML1 encode enzymes that utilize maltooligosaccharides as substrate to synthesize linear $\alpha$-glucans with $\alpha 1 \rightarrow 6$-linked glucose segments at the non-reducing end of $\alpha 1 \rightarrow 4$-linked glucose segments.

\section{Materials and methods}

Cloning of the $g t f W$ gene

A truncated version of the 4,6- $\alpha \mathrm{GT}-\mathrm{W}$ encoding $g t f W$ gene (GenBank accession number ABQ83597) was amplified from the genomic DNA of $L$. reuteri DSM 20016 using the primers For (NcoI) 5'-GAT GCA TCC ATG GGC ATA GAT GGT AAG AAC TAC CAC TTC GC-3' and Rev (BamHI) 5'-ATA TCG ATG GAT CCT ATT AGT GAT GGT GAT GGT GAT GAA TAT TTT CTT GGT TTG CAT AGT AAT CTG C-3' and high fidelity DNA polymerase (Fermentas), and cloned in pET15b (Novagen), yielding pET15b_4,6- $\alpha$ GT-W. This N-terminally truncated version of 4,6- $\alpha \mathrm{GT}-\mathrm{W}$ (amino acids 458-1363) carries a fused (His) $_{6}$-tag at its $\mathrm{C}$-terminal. The removal of the $\mathrm{N}$-terminal variable region is based on the cloning and expression of other GTFs, as this improves protein expression without affecting the catalytic properties (Kralj et al. 2004b).

\section{Cloning of the gtfML4 gene}

Previously, the 3'-end fragment of the 4,6- $\alpha$ GT-ML4 encoding gtfML4 gene (GeneBank accession number AAU08003.1) has been identified in $L$. reuteri ML1, located upstream of a glucansucrase gene ( $g t f M L 1)$. The $5^{\prime}$-end of the gtfML4 gene was obtained by inverse PCR. Briefly, genomic DNA of $L$. reuteri ML1 was digested by $B c u \mathrm{I}$ or $N s i \mathrm{I}$, and the products were ligated at a concentration of $\sim 10 \mathrm{ng} / \mu \mathrm{l}$ using T4 DNA ligase to obtain circular fragments. The ligation mixtures served as PCR template in an inverse PCR with the oligonucleotides HL115, 5'-TGA TCG TCC AGA TGT AGC-3' and 
HL116, 5'-CCA GTT ACT TTC ATA GAG G-3'. This yielded PCR fragments of $2 \mathrm{kbp}(B c u \mathrm{I})$ and $8 \mathrm{kbp}(N s i \mathrm{I})$, which were cloned in the pCR-XL-TOPO vector (Invitrogen). The obtained plasmids were used for DNA sequencing, yielding the 5 '-end of the gtfML4 gene.

Based on the DNA sequence obtained with the inverse PCR, the oligonucleotides HL117 (forward, NcoI), 5'-TTT TCC ATG GGG AAC CGC GTT GAT TAC TGG-3' and HL118 (reverse, $B g l$ II), 5'-AAA AGA TCT TAG TGA TGG TGA TGG TGA TGG TTG TTA AAA TTT AAT GAA ATT GC-3' were designed and used to amplify the gene from chromosomal DNA. The obtained fragment was cloned in pET15b (Novagen), yielding pET15b_4,6- $\alpha$ GT-ML4. This vector encodes an N-terminally truncated version of 4,6$\alpha$ GT-ML4 (amino acids 714-1620) and carries a fused (His) ${ }_{6}$-tag at its $\mathrm{C}$ terminus. Removal of the N-terminal variable region previously was shown to improve GTF protein expression without affecting catalytic properties (Kralj et al. 2004b).

\section{Expression and purification of 4,6- $\alpha \mathrm{GT}-\mathrm{W}$}

The 4,6- $\alpha$ GT-W protein was produced in Escherichia coli BL21(DE3)/pET15b_4,6- $\alpha$ GT-W cultivated in Luria broth containing $100 \mathrm{mg} / 1$ ampicillin. Protein expression was induced at an $\mathrm{OD}_{600}$ of $0.4-0.5$ by adding isopropyl $\beta$-D-1thiogalactopyranoside to $0.1 \mathrm{mM}$, and cultivation was continued for $4 \mathrm{~h}$ at $30^{\circ} \mathrm{C}$. Cells were harvested by centrifugation, washed in phosphate buffer $(50 \mathrm{mM}, \mathrm{pH} 8.0)$ and resuspended in phosphate buffer (50 mM, pH 8.0), containing $\mathrm{NaCl}$ $(250 \mathrm{mM})$, imidazole $(10 \mathrm{mM})$, and $\beta$-mercaptoethanol $(5 \mathrm{mM})$. Cell-free extracts were made by sonication followed by centrifugation $(10,000 \times g, 1 \mathrm{~h})$. The $4,6-\alpha \mathrm{GT}-\mathrm{W}$ protein was purified by nickel affinity chromatography using an 1-ml Hitrap IMAC HP column (GE Healthcare) and a gradient of $10-200 \mathrm{mM}$ imidazole in phosphate buffer (50 mM, pH 8.0), containing $\mathrm{NaCl}$ (250 mM). Fractions containing 4,6- $\alpha \mathrm{GT}-\mathrm{W}$ were pooled. The imidazole and $\mathrm{NaCl}$ were removed using a 5$\mathrm{ml}$ Hitrap desalting column (GE Healthcare) run with sodium phosphate buffer (50 mM, pH 8.0), and the protein was loaded on a 1-ml Resource-Q column (GE Healthcare). Protein was eluted with a gradient of $0-1 \mathrm{M} \mathrm{NaCl}$ in phosphate buffer (50 mM, pH 8.0). Fractions containing 4,6- $\alpha \mathrm{GT}-\mathrm{W}$ were transferred to sodium acetate buffer $(50 \mathrm{mM}$, pH 5.5) using a 5-ml Hitrap desalting column. Protein purity was assessed on $8 \%$ sodium dodecyl sulfate polyacrylamide gel electrophoresis (SDS-PAGE) and protein concentration measured with Bradford reagent (BioRad) and bovine serum albumin as standard.

Expression and purification of 4,6- $\alpha$ GT-ML4

The 4,6- $\alpha$ GT-ML4 protein was produced in E. coli BL21 (DE3)/pET15b_4,6- $\alpha$ GT-ML4 cultivated in Luria broth containing $100 \mathrm{mg} / \mathrm{l}$ ampicillin. Protein expression was induced at an $\mathrm{OD}_{600}$ of $0.4-0.5$ by adding isopropyl $\beta$-D-1thiogalactopyranoside to $0.1 \mathrm{mM}$, and cultivation was continued for $4 \mathrm{~h}$ at $30^{\circ} \mathrm{C}$ or $24 \mathrm{~h}$ at $18^{\circ} \mathrm{C}$. Cells were harvested by centrifugation, washed in Tris/ $\mathrm{HCl}$ buffer $(20 \mathrm{mM}$, $\mathrm{pH}$ 8.0), and resuspended in $10 \mathrm{ml}$ BPer lysis reagent (Pierce), followed by centrifugation $(10,000 \times g, 15 \mathrm{~min})$. The 4,6- $\alpha$ GT-ML4 protein was purified from inclusion bodies by washing the pellet once with $5 \mathrm{ml}$ BPer plus $2 \mathrm{mg}$ lysozyme for $10 \mathrm{~min}$ at room temperature, followed by four washes with $50 \mathrm{ml} 10$ times diluted BPer. Finally, the inclusion bodies were resuspended in $10 \mathrm{ml} 8 \mathrm{M}$ urea, $20 \mathrm{mM}$ Tris/ $\mathrm{HCl}$ (pH 8.0), $1 \mathrm{mM} \mathrm{CaCl}_{2}$, and $1 \mathrm{mM}$ DTT to obtain unfolded protein. Refolding was done by dialysis against $20 \mathrm{mM}$ Tris/ $\mathrm{HCl}\left(\mathrm{pH} \mathrm{8.0)}, 1 \mathrm{mM} \mathrm{CaCl}_{2}\right.$, and $1 \mathrm{mM}$ dithiothreitol. The 4,6- $\alpha$ GT-ML4 protein was then further purified by nickel affinity chromatography using a 1-ml Hitrap IMAC HP column (GE Healthcare). Following washing with $10 \mathrm{mM}$ imidazole in $20 \mathrm{mM}$ Tris/ $\mathrm{HCl}(\mathrm{pH} 8.0)$ with $1 \mathrm{mM} \mathrm{CaCl}_{2}$, the protein was eluted with $200 \mathrm{mM}$ imidazole in the same buffer. The imidazole was then removed using a 5-ml Hitrap desalting column (GE Healthcare) run with $20 \mathrm{mM}$ Tris/ $\mathrm{HCl}(\mathrm{pH} 8.0)$ and $1 \mathrm{mM} \mathrm{CaCl}_{2}$. Protein purity was assessed on $8 \%$ SDS-PAGE and protein concentration measured with Bradford reagent (BioRad) and bovine serum albumin as standard.

\section{Enzyme assays}

All reactions were performed in sodium acetate buffer (25 mM, pH 4.7) with $\mathrm{CaCl}_{2}(1 \mathrm{mM})$ at $37^{\circ} \mathrm{C}$, unless stated otherwise. The substrate spectra of the enzymes were investigated by incubating the various oligosaccharides $(10 \mathrm{mg}$, $100 \mathrm{mM}$; Sigma-Aldrich) with $25 \mu \mathrm{g} / \mathrm{ml}$ enzyme. The progress of the reactions was followed by high-pH anionexchange chromatography (HPAEC) (described below) and/or thin-layer chromatography (TLC) using silica gel 60F254 plates (Merck) run with butanol/ethanol/water $(5: 3: 3, v / v / v)$. TLC plates were developed with $10 \%$ $\mathrm{H}_{2} \mathrm{SO}_{4}$ in methanol/water $(1: 1, v / v)$, followed by heating at $100^{\circ} \mathrm{C}$.

For 4,6- $\alpha$ GT-W activity, the optimal $\mathrm{pH}$ and temperature were determined over the $\mathrm{pH}$ range of 3.5-6.5 (in $25 \mathrm{mM}$ sodium acetate buffer) and the temperature range of $20-60^{\circ} \mathrm{C}$, using $100 \mathrm{mM}$ maltose as substrate by following the release of glucose in time using the GOPOP kit (Megazyme) (Kaper et al. 2007). This assay could not be used with $4,6-\alpha$ GT-ML4 as it is hardly active with maltose. The optimal $\mathrm{pH}$ and temperature of 4,6- $\alpha$ GT-ML4 were therefore determined using $50 \mathrm{mM}$ maltotetraose as substrate and by following appearance of products on TLC plates.

The thermal inactivation rate of 4,6- $\alpha$ GT-W was determined by incubating the enzyme at a concentration of 
$0.26 \mathrm{mg} / \mathrm{ml}$ in sodium acetate buffer $(50 \mathrm{mM}, \mathrm{pH} 5.5)$ with $\mathrm{CaCl}_{2}(1 \mathrm{mM})$ at temperatures from $20^{\circ} \mathrm{C}$ to $55^{\circ} \mathrm{C}$ in a water bath for $10 \mathrm{~min}$. Samples were then cooled in an ice bath, and residual activity was measured by following the release of glucose using maltose as substrate. The $T_{50}$ is defined as the temperature at which $50 \%$ of the initial enzyme activity is retained after 10-min incubation.

Kinetic properties of 4,6- $\alpha$ GT-W were determined with maltose $(0-500 \mathrm{mM})$ as substrate and by following the release of glucose. Reactions were initiated by the addition of 4,6- $\alpha \mathrm{GT}-\mathrm{W}$ enzyme at a concentration of $64 \mathrm{nM}$. The rates were fitted to the Michaelis-Menten equation.

Isolation of individual products made by $4,6-\alpha \mathrm{GT}-\mathrm{W}$ via HPAEC

Twenty milligrams of maltose was incubated with $16 \mu \mathrm{g}$ $4,6-\alpha \mathrm{GT}-\mathrm{W}$ in $1.17 \mathrm{ml}$ sodium acetate buffer $(50 \mathrm{mM}$, $\mathrm{pH} 4.7$ ) at $37^{\circ} \mathrm{C}$ for 4 days. The reaction mixture was freeze-dried, dissolved in $200 \mu \mathrm{l}$ Milli-Q water, and 20- $\mu \mathrm{l}$ aliquots were loaded on a $9 \times 250 \mathrm{~mm}$ CarboPac PA- 1 column (Dionex), which was run with a gradient of 0-600 mM

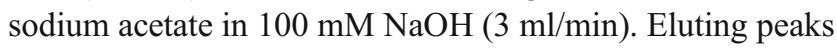
were collected manually and neutralized immediately with $4 \mathrm{M}$ acetic acid. The collected fractions were desalted on $150 \mathrm{mg}$ CarboGraph SPE columns (DiscoverySciences) using acetonitrile/water $=1: 3(v / v)$ as eluent, followed by lyophilization. The desalted fractions were analyzed by matrix-assisted laser-desorption ionization time-of-flight mass spectrometry (MALDI-TOF-MS) and ${ }^{1} \mathrm{H}$ nuclear magnetic resonance (NMR) spectroscopy. Fractions containing multiple oligosaccharides were separated again by HPAEC using a different elution gradient.

\section{4,6- $\alpha$ GT-W and 4,6- $\alpha$ GT-ML4 product analysis} with hydrolytic enzymes

Reaction products $(250 \mu \mathrm{g})$ of the enzyme incubations with maltose up to maltoheptaose were dissolved in $10 \mu \mathrm{l}$ sodium acetate buffer $(50 \mathrm{mM})$ and incubated for 1 day at $37^{\circ} \mathrm{C}$ with $\alpha$-amylase (porcine pancreas type I-A, $\mathrm{pH} 6.5$; SigmaAldrich), amyloglucosidase (Rhizopus, pH 5.0; Megazyme), or pullulanase M1 (Klebsiella planticola, $\mathrm{pH}$ 5.0; Megazyme). $\alpha$-Amylase cleaves $\alpha 1 \rightarrow 4$ glycosidic bonds in longer $\alpha 1 \rightarrow 4$ fragments, amyloglucosidase is an exo-acting enzyme that cleaves terminal $\alpha 1 \rightarrow 4$ and $\alpha 1 \rightarrow 6$ glycosidic bonds at the non-reducing end to form glucose, and pullulanase M1 cleaves $\alpha 1 \rightarrow 6$ glycosidic bonds at the reducing end of an $\alpha 1 \rightarrow 4$ glycosidic bond [in (-) $\alpha$-D-Glcp-( $(1 \rightarrow 4)-\alpha-$ D-Glcp-(1 $\rightarrow 6)$ - sequences] (Domań-Pytka and Bardowski 2004). The degree of degradation was assessed by TLC and/or HPAEC analysis.
High-pH anion-exchange chromatography

Carbohydrate samples were analyzed on a $4 \times 250 \mathrm{~mm}$ CarboPac PA-1 column using a Dionex DX500 workstation (Dionex), run with a gradient of $30-600 \mathrm{mM}$ sodium acetate in $100 \mathrm{mM} \mathrm{NaOH}(1 \mathrm{ml} / \mathrm{min})$, and detected with an ED40 pulsed amperometric detector. Calibration was done by running samples with known concentrations of glucose and maltotetraose.

Matrix-assisted laser-desorption ionization time-of-flight mass spectrometry

MALDI-TOF-MS experiments were performed on an Axima $^{\mathrm{TM}}$ mass spectrometer (Shimadzu), equipped with a nitrogen laser ( $337 \mathrm{~nm}, 3 \mathrm{~ns}$ pulse width). Positive-ion mode spectra were recorded using the reflector mode at a resolution of $5000 \mathrm{FWHM}$ and delayed extraction (450 ns). The accelerating voltage was $19 \mathrm{kV}$ with a grid voltage of $75.2 \%$; the mirror voltage ratio was 1.12 , and the acquisition mass range was 200-3,000 Da. Samples $(1 \mu \mathrm{l})$ were mixed in $1: 1$ ratio with $10 \mathrm{mg} / \mathrm{ml} \mathrm{2,5-dihydroxybenzoic} \mathrm{acid} \mathrm{in}$ acetonitrile/water $=1: 1(\mathrm{v} / \mathrm{v})$. The compounds fly as sodium ion adduct.

\section{Linkage analysis}

Samples ( $\sim 2 \mathrm{mg}$ ) were permethylated using $\mathrm{CH}_{3} \mathrm{I}$ and solid $\mathrm{NaOH}$ in $\mathrm{Me}_{2} \mathrm{SO}$ as described previously (Ciucanu and Kerek 1984). After hydrolysis with $2 \mathrm{M}$ trifluoroacetic acid $\left(2 \mathrm{~h}, 120^{\circ} \mathrm{C}\right)$, the partially methylated monosaccharides were reduced with $\mathrm{NaBD}_{4}(2 \mathrm{~h}$ at room temperature, aqueous solution). Conventional work-up, comprising neutralization (by adding $4 \mathrm{M}$ acetic acid) and removal of boric acid by co-evaporation with methanol, followed by acetylation with pyridine/acetic anhydride $(1: 1, v / v)\left(30 \mathrm{~min}, 120^{\circ} \mathrm{C}\right)$, yielded mixtures of partially methylated alditol acetates, which were analyzed by gas-liquid chromatography electron impact mass spectrometry.

\section{NMR spectroscopy}

Resolution-enhanced 1D 500-MHz ${ }^{1} \mathrm{H}$ NMR spectra were recorded in $\mathrm{D}_{2} \mathrm{O}$ on a Varian Inova Spectrometer (NMR Center, University of Groningen) or a Bruker DRX-500 spectrometer (Bijvoet Center, Department of NMR Spectroscopy, Utrecht University) at probe temperatures of $300 \mathrm{~K}$. Prior to analysis, samples were exchanged twice in $\mathrm{D}_{2} \mathrm{O}$ (99.9 atm\% D, Cambridge Isotope Laboratories, Inc.) with intermediate lyophilization and then dissolved in $0.6 \mathrm{ml} \mathrm{D}_{2} \mathrm{O}$. Suppression of the HOD signal (on the Bruker DRX-500 spectrometer only) was achieved by applying a WEFT pulse sequence. Chemical shifts $(\delta)$ 
are expressed in parts per million by reference to internal acetone $\left(\delta 2.225\right.$ for $\left.{ }^{1} \mathrm{H}\right)$.

\section{Sequence alignments}

The amino acid sequences of GH70 proteins were compared using ClustalW2 run at EMBL-EBI (http://www.ebi.ac.uk) (Larkin et al. 2007; Goujon et al. 2010).

\section{Results}

Cloning of the gtfW and $g t f M L 4$ genes

L. reuteri DSM 20016 possesses a gtfW gene (4092 bps; GeneBank accession ABQ83597), which encodes a 154$\mathrm{kDa}$ protein, designated 4,6- $\alpha \mathrm{GT}-\mathrm{W}$. Sequence comparison indicates that, in analogy with other GH70 enzymes, 4,6$\alpha$ GT-W possesses a variable $\mathrm{N}$-terminal region (amino acids 1-427), a catalytic domain [amino acids 428-1223; e.g., domains $\mathrm{A}, \mathrm{B}$, and $\mathrm{C}$ in the crystal structure of GTFs (Vujičić-Žagar et al. 2010; Ito et al. 2011)] and a Cterminal region (amino acids 1224-1363). The signal sequence predictor SignalP 3.0 does not predict an N-terminal signal sequence for $4,6-\alpha \mathrm{GT}-\mathrm{W}$. The enzyme shares $47 \%$ sequence identity with $4,6-\alpha \mathrm{GT}-\mathrm{B}$ of $L$. reuteri 121 ; the similarity of domains $\mathrm{A}, \mathrm{B}$, and $\mathrm{C}$ is much higher with $70 \%$ sequence identity. A protein BLAST search identifies three hypothetical GH70 enzymes in the genomes of $L$. reuteri JCM 1112 (Morita et al. 2008), L. reuteri MM2-3 (UniProt accession C0YXW9) and L. reuteri MM4-1A (UniProt accession C2F8B9) that are virtually identical to 4,6- $\alpha \mathrm{GT}-\mathrm{W}$, the only difference being that the three hypothetical proteins have an extra 125 amino acids at their $\mathrm{N}$ termini. The next hit in the BLAST search is a hypothetical GH70 protein (UniProt accession C0X0D3) from Lactobacillus fermentum ATCC 14931 with $71 \%$ sequence identity to $4,6-\alpha$ GT-W.

Previously, it was shown that $L$. reuteri ML1 possesses a gtfML1 gene, which encodes a glucansucrase and that the direct upstream DNA sequence shows similarity to GH70 genes (Kralj et al. 2004a), though a full gene sequence was not obtained. This gene fragment was designated as (part of) gtfML4, and the encoded protein fragment showed most sequence similarity to $4,6-\alpha$ GT-B of $L$. reuteri 121 . Therefore, we isolated the full $g t f M L 4$ gene by inverse PCR. The gene is 4863 nucleotides and encodes a protein of $180 \mathrm{kDa}$, which has the typical arrangement of a GH70 family enzyme, with an N-terminal signal sequence of 39 amino acids as predicted by the SignalP 3.0 (Bendtsen et al. 2004), a large variable N-terminal region (amino acids 40-738), a catalytic domain (amino acids 739-1486), and a C-terminal region (amino acids 1487-1620). 4,6- $\alpha$ GT-ML4 shares $96 \%$ sequence identity with GTF-106B of $L$. reuteri TMW1.106, which has been reported to slowly hydrolyze sucrose but does not synthesize a polymer from sucrose (Kaditzky et al. 2008 ) and $86 \%$ and $46 \%$ sequence identity with $4,6-\alpha$ GT-B and 4,6- $\alpha \mathrm{GT}-\mathrm{W}$, respectively.

Sequence alignments of the GH70 enzymes revealed differences in the amino acids forming the acceptor subsites $+1 /+2$ between 4,6- $\alpha$ GTs and GTFs (Table 1 ). In addition, it showed that the loop connecting domains IV and B (residues 932-943 in GTF-180), containing the subsite +1 residue 938 , is eight residues longer in 4,6- $\alpha$ GTs compared to GTFs (Fig. 1). Phylogenetic analysis of the GH70 protein sequences revealed that the 4,6- $\alpha \mathrm{GT}$ proteins form a small but clearly separate cluster (Suppl. Info. Fig. S1).

Table 1 Comparison of the amino acid residues at the acceptor subsites +1 and +2 of GH70 enzymes

\begin{tabular}{|c|c|c|c|}
\hline & GTFs & $4,6-\alpha \mathrm{GTs}$ & Function in GTFs \\
\hline \multicolumn{4}{|c|}{ Subsite +1} \\
\hline $938^{\mathrm{a}}$ & $\mathrm{D}, L, \mathrm{I}^{\mathrm{b}, \mathrm{c}}$ & G & $4,6-\alpha$ GTs have a longer loop here \\
\hline 981 & $L$ & $\mathrm{~L}$ & - \\
\hline 1028 & $D$ & $\mathrm{D}$ & - \\
\hline 1029 & $N$ & $\mathrm{~N}$ & - \\
\hline 1065 & $W, \mathrm{G}$ & $\mathrm{Y}$ & - \\
\hline 1140 & $Q$ & $\mathrm{~N}$ & Glycosidic bond specificity ${ }^{\mathrm{d}}$ \\
\hline \multicolumn{4}{|c|}{ Subsite +2} \\
\hline 978 & $\mathrm{Y}, \mathrm{F}, A, \mathrm{Q}, \mathrm{S}$ & $\mathrm{P}$ & $\begin{array}{l}\text { Loop region with variation in } \\
\text { length }\end{array}$ \\
\hline 1028 & $D$ & $\mathrm{D}$ & - \\
\hline 1065 & $W, \mathrm{G}$ & $\mathrm{Y}$ & - \\
\hline 1088 & $R, \mathrm{H}, \mathrm{K}, \mathrm{T}, \mathrm{S}$ & $\mathrm{F}$ & - \\
\hline 1137 & $S, \mathrm{~N}$ & Q & Glycosidic bond specificity $^{\mathrm{d}, \mathrm{e}}$ \\
\hline 1141 & $\mathrm{~T}, D, \mathrm{~S}, \mathrm{~A}, \mathrm{G}$ & $\mathrm{L}, \mathrm{V}$ & Glycosidic bond specificity ${ }^{\mathrm{f}}$ \\
\hline
\end{tabular}

The information is based on the crystal structure of GTF-180 of $L$. reuteri 180 [protein databank files 3HZ3 and 3KLL (Vujičić-Žagar et al. 2010)], and the amino acids are numbered according to GTF-180. Eighty-eight GH70 sequences were used for the alignment, including the three 4,6- $\alpha \mathrm{GTs}$ (B, W, and ML4) and the two putative 4,6- $\alpha \mathrm{GTs}$ of Lactobacillus reuteri JCM 1112 (Uniprot accession number B2G8K2) and Lactobacillus reuteri TMW1.106 (Uniprot accession number A9Q0J0). The equivalent residues in the 4,6- $\alpha \mathrm{GTs}$ are based on sequence alignments. Catalytic residues are excluded from the comparison as they are conserved in both GTFs and 4,6- $\alpha$ GTs

${ }^{\text {a }}$ Amino acids are numbered according to GTF-180 of L. reuteri 180 of which the three dimensional structure is known (Vujičić-Žagar et al. 2010)

${ }^{\mathrm{b}}$ The amino acids are given in a descending order of occurrence

${ }^{\mathrm{c}}$ The residues in GTF-180 are indicated in italics

${ }^{\mathrm{d}}$ van Leeuwen et al. (2009)

${ }^{\mathrm{e}}$ Irague et al. (2011)

${ }^{\mathrm{f}}$ Shimamura et al. (1994) 


$\begin{array}{ll}\text { GTF-A } & 929-\text { SENVN-------FSGIQFQGGFLKYEN-948 } \\ \text { GTF-ML1 } & 930-\text { SENED-------FGGLQLQGGELKYVN-949 } \\ \text { GTF-180 } & 930-\text { SENVD-------YGGLQLQGGFLKYVN-949 } \\ \text { GTF-O } & 929-\text { TENVN-------YSGLQFQGGFLKYEN-948 } \\ \text { GTF-SI } & 374-\text { SEKPE--------DDHLQKGALLYSN-391 } \\ \text { GTF-DSRE } & 429-\text { SES--------KGNDHLQGGALLYVN-446 } \\ \text { 4,6- } \alpha \text { GT-ML4 } & 904-\text { SELSLQSMPNYRPDESGTVDSDQVIFVN-931 } \\ \text { 4,6- } \alpha \text { GT-B } & 903-\text { SELSLQSMPNYRPDKSGTIDSDQVIFVN-930 } \\ \text { 4,6- } \alpha \text { GT-W } & 640-\text { SELPVEYSNGYVPDVSGSIDNNQLIFIN-667 }\end{array}$

Fig. 1 The loop connecting the domains IV and B is longer in 4,6$\alpha$ GTs then in GTFs. The sequence alignment shows the region around the subsite +1 residue L938 (indicated by the triangle) of GTF-180. The sequences used are as follows: GTF-A (Q5SBL9) of Lactobacillus reuteri 121 ; GTF-180 (Q5SBN3) of $L$. reuteri 180 ; GTF-O (Q4JLC7)

Expression and basic properties of $4,6-\alpha \mathrm{GT}-\mathrm{W}$

and 4,6- $\alpha$ GT-ML4

N-terminally truncated versions of 4,6- $\alpha \mathrm{GT}$-W (amino acids 458-1363) and 4,6- $\alpha$ GT-ML4 (amino acids 714-1620) were expressed in E. coli. 4,6- $\alpha \mathrm{GT}-\mathrm{W}$ was purified by His-tag affinity and anion-exchange chromatography, yielding $1.0 \mathrm{mg}$ of pure protein per liter of culture. The enzyme displays optimal activity around $\mathrm{pH} 4.5$ and $40-45^{\circ} \mathrm{C}$ and is resistant to thermal inactivation up to $45^{\circ} \mathrm{C}$ in sodium acetate buffer (pH 5.5), but at $51{ }^{\circ} \mathrm{C}$, it loses half of its activity in $10 \mathrm{~min}$. 4,6- $\alpha$ GT-ML4 was purified from inclusion bodies using urea unfolding, refolding by dialysis and subsequent His-tag affinity chromatography, yielding $1.2 \mathrm{mg}$ of soluble and pure 4,6- $\alpha$ GT-ML4 protein per liter of culture. The enzyme displays optimal activity around $\mathrm{pH} 4.5$ and $40^{\circ} \mathrm{C}$.

\section{4,6- $\alpha \mathrm{GT}$-W and 4,6- $\alpha \mathrm{GT}$-ML4 disproportionate maltooligosaccharides}

The substrate preference of the 4,6- $\alpha$ GT-W and 4,6- $\alpha$ GTML4 enzymes was explored by incubating them with various oligosaccharides. As shown by TLC, both enzymes use linear maltooligosaccharides $[(1 \rightarrow 4)-\alpha$-D-glucooligosaccharides] as substrate, forming a range of shorter and longer products (Fig. 2), but not sucrose (the typical substrate of GH70 enzymes), trehalose, raffinose, 1-kestose, nystose, isomaltose, and isomaltopentaose. The difference between the two enzymes is that $4,6-\alpha$ GT-W already efficiently disproportionates the disaccharide maltose, whereas $4,6-\alpha \mathrm{GT}$ ML4 requires maltotetraose or longer maltooligosaccharides (Fig. 2). Besides oligomeric material, TLC analysis showed that both enzymes also produce polymeric material [degree of polymerisation (DP) $>10$ ] (Fig. 2). Note that the polymeric material is not of very high molecular weight. For the homolog enzyme 4,6- $\alpha$ GT-B, we showed that the larger of L. reuteri ATCC 55730; GTF-ML1 (Q5SBN0) of L. reuteri ML1; GTF-DSRE (Q8G9Q2) of Leuconostoc mesenteroides NRRL B-1299; GTF-SI (P13470) of Streptococcus mutans GS-5; 4,6- $\alpha$ GT-B (Q5SBM0) of $L$. reuteri $121 ; 4,6-\alpha \mathrm{GT}-\mathrm{W}$ (A5VL73) of L. reuteri DSM20016; 4,6- $\alpha$ GT-ML4 (Q5SBN1) of L. reuteri ML1
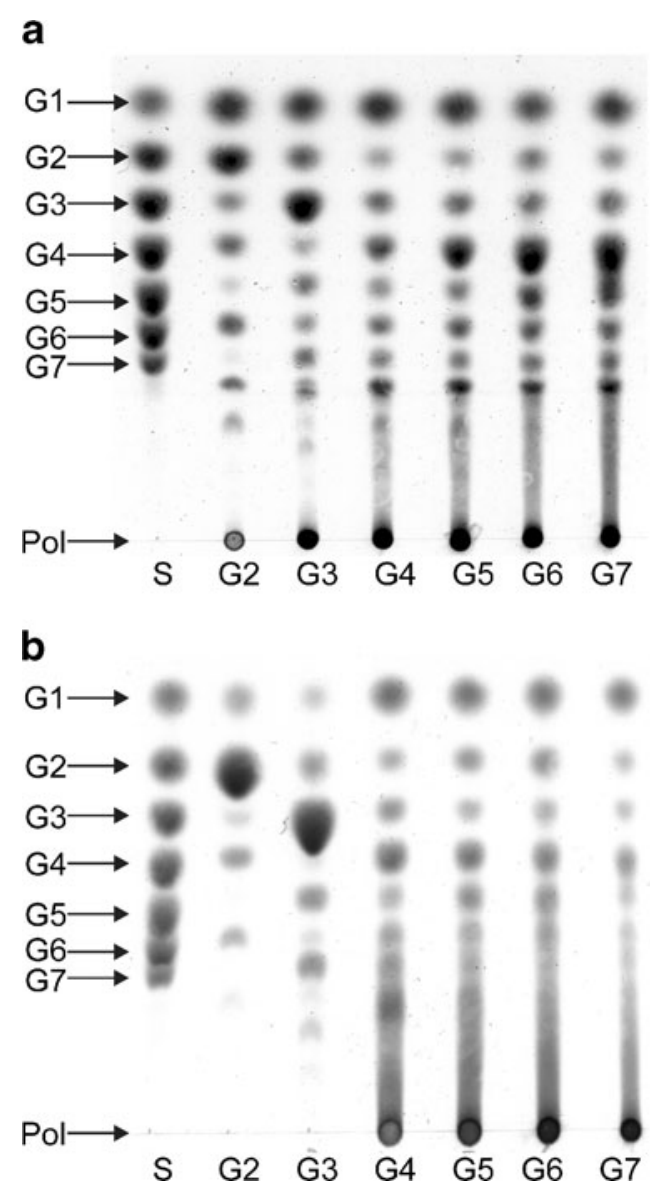

Fig. 2 4,6- $\alpha$ GT-W and 4,6- $\alpha$ GT-ML4 disproportionate maltooligosaccharides [( $1 \rightarrow 4)-\alpha$-D-glucooligosaccharides]. TLC analysis of product mixtures from maltooligosaccharide incubations with a $4,6-\alpha \mathrm{GT}-\mathrm{W}$ and b 4,6- $\alpha$ GT-ML4. Conditions: $\mathrm{pH} 4.7$ and $37^{\circ} \mathrm{C}, 40 \mathrm{~h}, 25 \mu \mathrm{g} / \mathrm{ml}$ enzyme. $S$ standard: glucose (G1) to maltoheptaose (G7); Pol polymer; lanes $2-7$ are the product mixtures obtained from maltose $(\mathrm{G} 2)$ to maltoheptaose (G7) 
molecules synthesized from maltoheptaose had DPs below 50 (Dobruchowska et al. 2012).

The initial rate of 4,6- $\alpha \mathrm{GT}$-W with maltose was determined by measuring the release of glucose (as maltose + maltose $\rightarrow$ a DP3 compound + glucose) using glucose oxidase, displaying a $k_{\mathrm{cat}}$ of $37 \pm 4 \mathrm{~s}^{-1}$ and a $K_{\mathrm{M}}$ of $150 \pm$ $40 \mathrm{mM}$. The enzyme also processes maltopentaose, yielding maltotetraose + glucose (hydrolysis) or maltotetraose + a DP6 compound (transglycosylation). With $43 \mathrm{mM}$ of maltopentaose as substrate, the initial rate of glucose formation was $56 \%$ of that of maltotetraose formation, showing that the enzyme is rather hydrolytic at the start of the reaction. However, when reaction products start to accumulate, transglycosylation becomes more efficient, as the reaction products are better acceptor substrates than maltopentaose.

4,6- $\alpha$ GT-W and 4,6- $\alpha$ GT-ML4 form $\alpha 1 \rightarrow 6$ glycosidic bonds

HPAEC analysis of the reaction products of the incubations of 4,6- $\alpha$ GT-W and 4,6- $\alpha$ GT-ML4 with maltooligosaccharides [( $1 \rightarrow 4)-\alpha$-D-glucooligosaccharides] of DP2 to DP7 (for DP7, see Suppl. Info. Fig. S2) revealed the formation of products with retention times different from those of maltooligosaccharides. The elution profiles of both enzyme incubations per DP also showed that the product ensembles are not identical, despite the fact that both reaction mixtures contain the same type of glycosidic linkages, at nearly identical ratios, as discussed below.

${ }^{1} \mathrm{H}$ NMR analysis of the various product mixtures obtained with 4,6- $\alpha$ GT-W and 4,6- $\alpha$ GT-ML4 showed the presence of $\alpha 1 \rightarrow 4$ linkages (H-1, $\delta \sim 5.40)$ and newly formed $\alpha 1 \rightarrow 6$ linkages (H-1, $\delta \sim 4.97$; broad signal). As typical examples, Fig. 3 presents the very similar ${ }^{1} \mathrm{H}$ NMR spectra for the product mixtures generated from maltohexaose, showing a linkage ratio $\alpha 1 \rightarrow 4: \alpha 1 \rightarrow 6=50: 50$ for 4,6 $\alpha$ GT-W (Fig. 3a) and a linkage ratio $\alpha 1 \rightarrow 4: \alpha 1 \rightarrow 6=53: 47$ for 4,6- $\alpha$ GT-ML4 (Fig. 3b). The slightly different built-up of the broad H-1 signal at $\delta \sim 4.97$, comparing both cases, supports the HPAEC observation that different product ensembles are formed. The reducing-end glucose residues are 4-substituted [-(1 $\rightarrow 4)-\mathrm{D}-\mathrm{Glc} p ; \mathrm{R} \alpha \mathrm{H}-1, \delta 5.225 ; \mathrm{R} \beta \mathrm{H}-$ $1, \delta 4.652)]$. The spectra also revealed the presence of free glucose $(\mathrm{G} \alpha \mathrm{H}-1, \delta 5.225$; G $\beta \mathrm{H}-1, \delta 4.637)$. Furthermore, small amounts of six-substituted reducing-end glucose residues [-(1 $\rightarrow 6)$-D-Glc $p$; $\mathrm{R} \alpha \mathrm{H}-1, \delta 5.241 ; \mathrm{R} \beta \mathrm{H}-1, \delta 4.670)$ were detected, demonstrating that both enzymes can use glucose as acceptor to make isomaltose, which can then be further elongated by the enzyme. The ${ }^{1} \mathrm{H}$ NMR spectra (Fig. 3) reveal that both $4,6-\alpha$ GT-W and $4,6-\alpha$ GT-ML4 create linear structures only, as no signal typical for $(1 \rightarrow 4,6)-\alpha$-D-Glc $p$ - $(1 \rightarrow 4)$ - branches is seen [H-1, $\delta$ 5.36)] (van Leeuwen et al. 2008a).
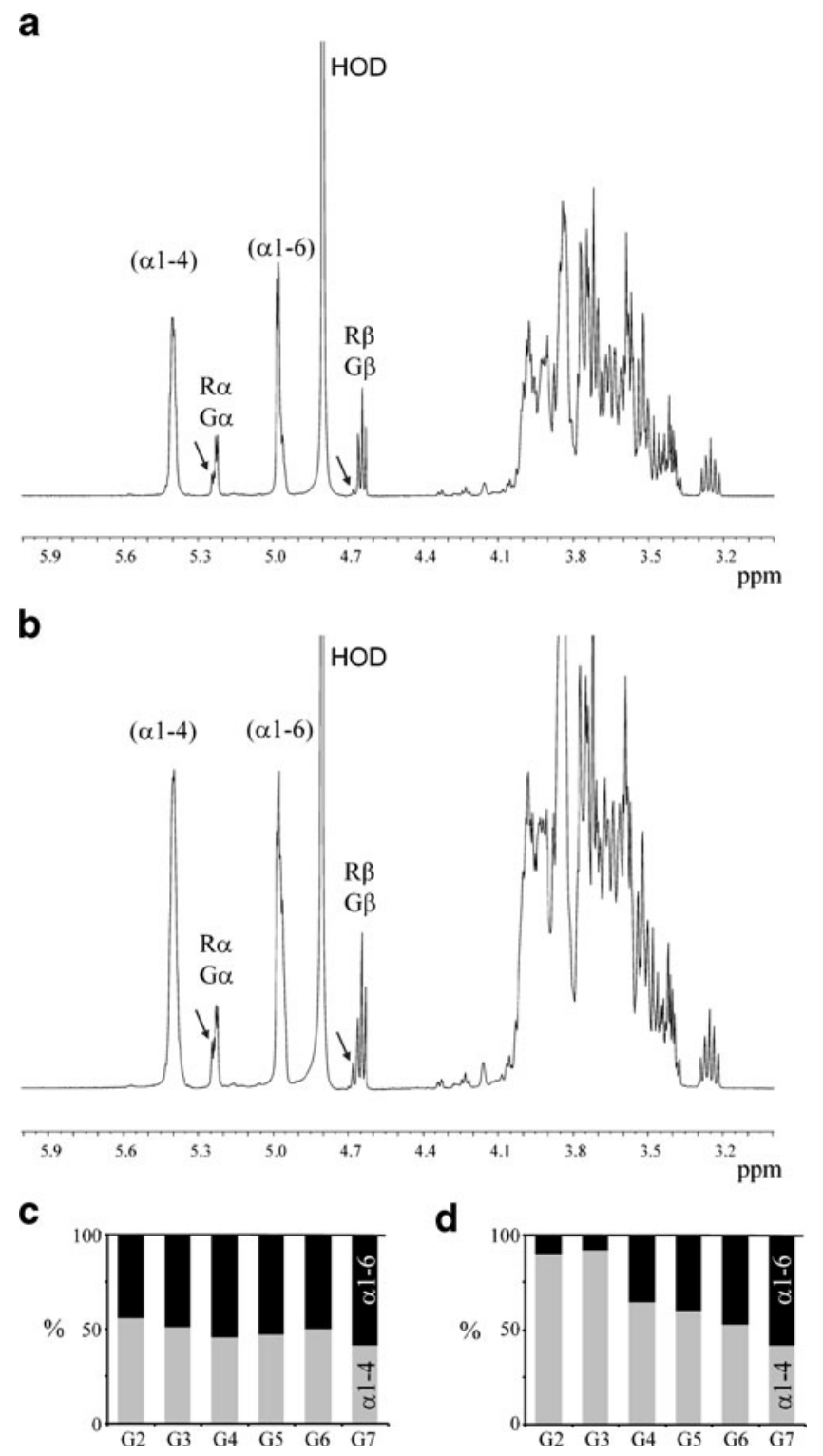

Fig. $34,6-\alpha$ GT-W and 4,6- $\alpha$ GT-ML4 form $\alpha 1 \rightarrow 6$ glycosidic linkages. $500-\mathrm{MHz}{ }^{1} \mathrm{H}$ NMR spectra (without water suppression) of product mixtures obtained from maltohexaose (DP6) incubations with a $4,6-\alpha$ GT-W or b 4,6- $\alpha$ GT-ML4. The bar diagrams give the percentage of $\alpha 1 \rightarrow 4$ (light gray) and $\alpha 1 \rightarrow 6$ glycosidic linkages (black) in the product mixtures obtained from maltose $(\mathrm{G} 2)$ to maltoheptaose $(\mathrm{G} 7)$ incubated with $\mathbf{c} 4,6-\alpha \mathrm{GT}-\mathrm{W}$ or $\mathbf{d} 4,6-\alpha \mathrm{GT}-\mathrm{ML} 4$. The anomeric signals reflecting the $\alpha 1 \rightarrow 4$ and $\alpha 1 \rightarrow 6$ glycosidic linkages are indicated by ( $\alpha 1-4)$ and ( $\alpha 1-6)$, respectively. The anomeric signals assigned as $G \alpha /$ $\beta$ and $R \alpha / \beta$ indicate the presence of free glucose and the presence of reducing $-(1 \rightarrow 4)-\mathrm{D}-\mathrm{Glc} p$ units, respectively. The arrows in the spectra of the product mixtures indicate the presence of small amounts of reducing $-(1 \rightarrow 6)-\mathrm{D}-\mathrm{Gl} p$ units

For the conversion of maltotetraose by $4,6-\alpha \mathrm{GT}-\mathrm{W}$ (Suppl. Info. Fig. S3), methylation analysis supports the conclusion that only 4-O- and 6-O-substituted glucose residues are present, but no branched residues, thereby demonstrating that indeed the products are linear. Interestingly, the ${ }^{1} \mathrm{H}$ NMR analysis revealed that in case of 
4,6- $\alpha \mathrm{GT}-\mathrm{W}$ the size of the substrate had only little influence on the $\alpha 1 \rightarrow 4: \alpha 1 \rightarrow 6$ glycosidic linkage ratio in the product mixtures (Fig. 3c), whereas for $4,6-\alpha \mathrm{GT}$ ML4 the percentage of $\alpha 1 \rightarrow 6$ glycosidic linkages introduced increased with increasing size of the substrate (Fig. 3d). In conclusion, both 4,6- $\alpha$ GT-W and 4,6$\alpha$ GT-ML4 convert $(1 \rightarrow 4)-\alpha$-D-glucooligosaccharides in linear $\alpha$-glucans with $\alpha 1 \rightarrow 4$ and $\alpha 1 \rightarrow 6$ glycosidic linkages.

Purification and characterization of 4,6- $\alpha \mathrm{GT}-\mathrm{W}$ products

To gain more insight in the carbohydrate structures made by 4,6- $\alpha \mathrm{GT}-\mathrm{W}$, the reaction mixture obtained from maltose was separated by HPAEC (Fig. 4). The isolated compounds were analyzed by MALDI-TOF-MS for their molecular mass and for their purity in terms of DP. Fractions containing multiple oligosaccharides were separated again by HPAEC using a different elution gradient. The structures of the isolated compounds were established by $1 \mathrm{D}{ }^{1} \mathrm{H}$ NMR spectroscopy making use of a ${ }^{1} \mathrm{H}$ NMR library data base of $\alpha$-glucans (van Leeuwen et al. 2008b; Dobruchowska et al. 2012). Besides glucose, the starting substrate maltose and panose [ $\alpha$-D-Glc $p$ - $(1 \rightarrow 6)-\alpha$-D-Glc $p-(1 \rightarrow 4)-\mathrm{D}-\mathrm{Glc} p$ ], four compounds could be identified, i.e., $\alpha$-D-Glc $p-(1 \rightarrow 4)-\alpha-D-$ Glc $p$ - $(1 \rightarrow 4)-\mathrm{D}-\mathrm{Glc} p$ (maltotriose), $\alpha$-D-Glc $p-(1 \rightarrow 6)-\alpha$-DGlc $p$ - $(1 \rightarrow 6)-\alpha-\mathrm{D}-\mathrm{Glc} p-(1 \rightarrow 4)-\mathrm{D}-\mathrm{Glc} p, \alpha$-D-Glc $p-(1 \rightarrow 6)-\alpha-$ D-Glc $p$ - $(1 \rightarrow 6)-\alpha$-D-Glc $p$ - $(1 \rightarrow 6)-\alpha$-D-Glc $p$ - $(1 \rightarrow 4)-\mathrm{D}-\mathrm{Glc} p$,

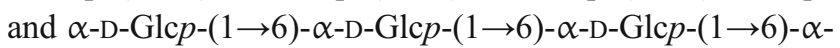

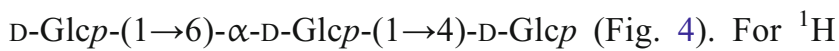
NMR spectra, see (Suppl. Info. Fig. S4).
Enzymatic hydrolysis of the 4,6- $\alpha \mathrm{GT}-\mathrm{W}$ and $4,6-\alpha \mathrm{GT}-\mathrm{ML} 4$ products

To investigate to what extent the $\alpha$-glucan product mixtures made from maltose up to maltoheptaose using 4,6- $\alpha \mathrm{GT}-\mathrm{W}$ and 4,6- $\alpha$ GT-ML4 were resistant to $\alpha$-amylase digestion, they were incubated with a high dose of pig pancreatic $\alpha$ amylase. Subsequent TLC analysis (Fig. 5) revealed small oligosaccharides but also larger oligosaccharides and polymeric material. These data thus shows that both $4,6-\alpha \mathrm{GTs}$ synthesize $\alpha$-glucans partly resistant to the endo- $\alpha 1 \rightarrow 4$ hydrolase action of $\alpha$-amylase. The product mixtures are, however, completely degraded to glucose by amyloglucosidase (data not shown), demonstrating that the products are composed of $\alpha 1 \rightarrow 4$ and $\alpha 1 \rightarrow 6$ glycosidic bonds only, which is in agreement with the ${ }^{1} \mathrm{H}$ NMR analysis.

4,6- $\alpha$ GT-W mainly synthesizes $\alpha 1 \rightarrow 6$ glycosidic linkages, but also occasionally $\alpha 1 \rightarrow 4$ glycosidic bonds, as maltotriose is one of the products made from maltose (Fig. 4). To explore whether 4,6- $\alpha$ GT-W also elongates via an $\alpha 1 \rightarrow 4$ glycosidic bond onto oligosaccharides of which the non-reducing glucose moiety is attached via an $\alpha 1 \rightarrow 6$ linkage, thereby creating $-\alpha$-D-Glc $p-(1 \rightarrow 4)-\alpha-\mathrm{D}-\mathrm{Glc} p$ $(1 \rightarrow 6)$ - elements, the product mixtures obtained from maltose up to maltoheptaose were treated with pullulanase type M1. This enzyme hydrolyzes $\alpha 1 \rightarrow 6$ glycosidic linkages in $(-) \alpha$-D-Glc $p$ - $(1 \rightarrow 4)-\alpha$-D-Glc $p$ - $(1 \rightarrow 6)$ - sequences only. Comparison of the HPAEC elution profiles before and after pullulanase treatment showed only a few differences in the larger oligosaccharide and polymeric fractions (Suppl. Info. Fig. S5), demonstrating that $4,6-\alpha \mathrm{GT}-\mathrm{W}$ occasionally synthesizes such a sequence.

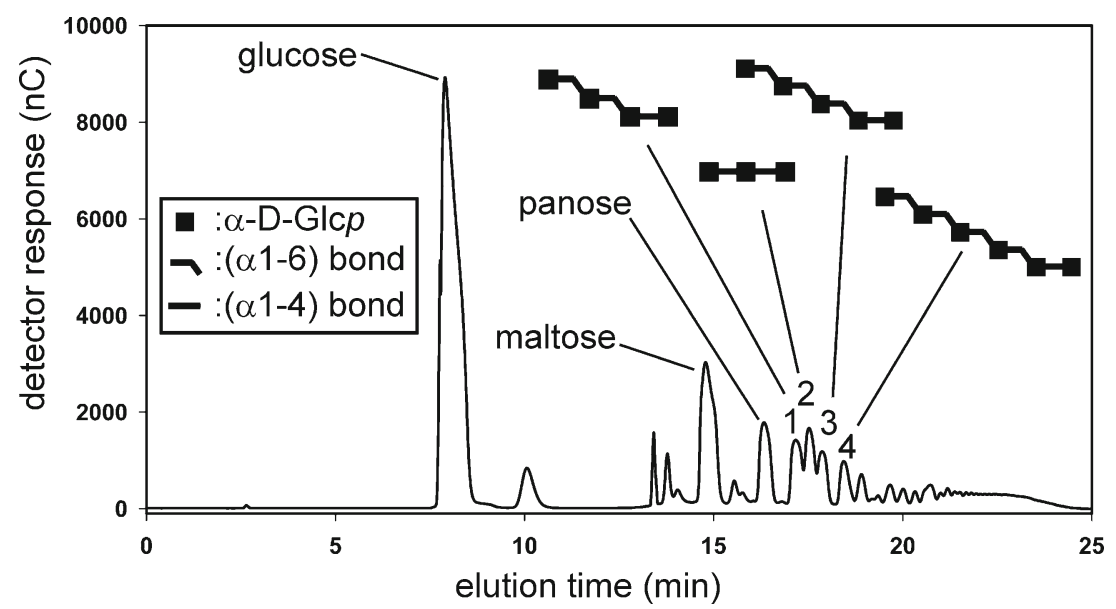

Fig. 4 HPAEC elution profile of the reaction mixture obtained from maltose, incubated with $4,6-\alpha \mathrm{GT}-\mathrm{W}$ at $\mathrm{pH} 4.7$ and $37^{\circ} \mathrm{C}$ for 4 days. Fractions 1-4 were collected, and after desalting, the products were characterized by ${ }^{1} \mathrm{H}$ NMR spectroscopy (Suppl. Info. Fig. 4a-d), making use of a ${ }^{1} \mathrm{H}$ NMR library data base of $\alpha$-glucans (van Leeuwen et al. 2008b; Dobruchowska et al. 2012) (and references cited therein). Identified structures are indicated in symbol notation above the peaks; for the complete names, see text 


\section{Discussion}

It was generally accepted that all GH70 enzymes synthesize $\alpha$-glucans from sucrose, until we recently demonstrated that L. reuteri 121 encodes a GH70 enzyme (called 4,6- $\alpha$ GT-B) that uses $(1 \rightarrow 4)$ - $\alpha$-glucans, but not sucrose, as substrate (Kralj et al. 2011; Dobruchowska et al. 2012). Even though it is known that some GH70 enzymes possess a low disproportionating activity with $\alpha$-glucans in addition to their main activity (Binder et al. 1983), it was surprising to find a GH70 enzyme to be so effective in utilizing $(1 \rightarrow 4)$ - $\alpha$-glucans as glucose donor because the glycosidic linkage of sucrose is labile compared with the $\alpha 1 \rightarrow 4$ glycosidic bond. Phylogenetic tree analysis of the GH70 protein sequences

\section{a}

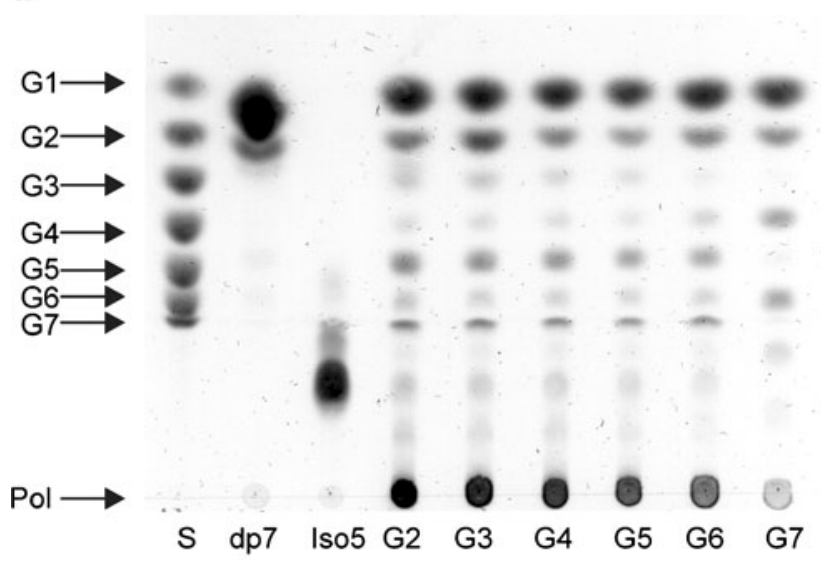

b

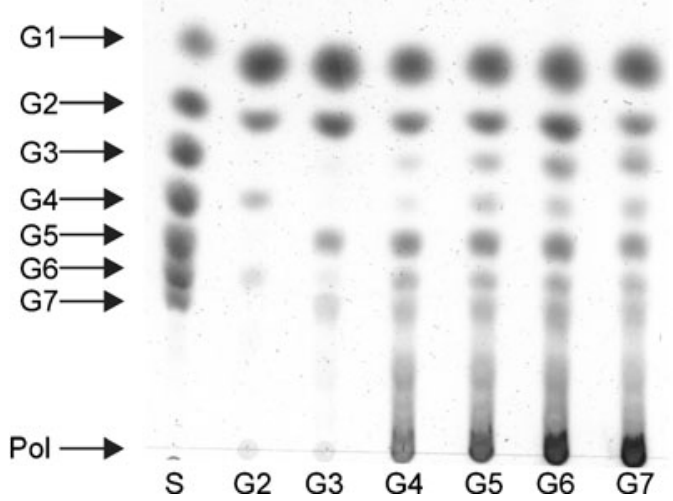

Fig. $54,6-\alpha$ GT-W and 4,6- $\alpha$ GT-ML4 generate $\alpha$-amylase resistant $\alpha$ glucans. TLC analysis of the product mixtures from maltooligosaccharide (G2-G7) incubations with 4,6- $\alpha$ GT-W (a) and 4,6- $\alpha$ GT-ML4 (b) (see Fig. 2), after treatment with a high-dose of pig pancreatic $\alpha$ amylase. $S$ standard: glucose (G1) to maltoheptaose (G7); Pol polymer. Lanes 2-7 are the product mixtures from G2 to G7, generated by the sequential 4,6- $\alpha \mathrm{GT} / \alpha$-amylase incubations. The upper panel shows as controls isomaltopentaose (Iso5; not degraded by $\alpha$-amylase) and maltoheptaose (dp7; degraded to maltose and glucose by $\alpha$-amylase). Note that Iso5 is not entirely pure revealed that 4,6- $\alpha$ GT-B clusters with a few hypothetical proteins (Kralj et al. 2011) (Suppl. Info. Fig. S1). Here, we show that the hypothetical GH70 proteins of L. reuteri strains DSM 20016 and ML1 encode enzymes that convert maltooligosaccharides $[(1 \rightarrow 4)-\alpha$-D-glucooligosaccharides $]$ into linear $\alpha$-glucans (in fact isomalto/maltooligosaccharides) with about $50 \% \quad \alpha 1 \rightarrow 6$ glycosidic bonds. It thus appears that $4,6-\alpha \mathrm{GT}$ activity is a common activity within the GH70 family.

The 4,6- $\alpha$ GT products are synthesized by cleaving off the non-reducing glucose moiety of a $(1 \rightarrow 4)$ - $\alpha$-glucan and transferring the glucose moiety to the HO-6 function of the non-reducing end of an acceptor $\alpha$-glucan chain $[\mathrm{a}(1 \rightarrow 4)$ $\alpha$-glucan or a $(1 \rightarrow 4)$ - $\alpha$-glucan already elongated with a number of $(\alpha 1 \rightarrow 6)$-linked glucose residues] (Fig. 6). The enzymes possess, in addition, minor hydrolytic and $\alpha 1 \rightarrow 4$ transglycosylase activities. All three disproportionating GH70 4,6- $\alpha$ GT enzymes characterized so far synthesize $\alpha 1 \rightarrow 6$ glycosidic bonds and occasionally an $\alpha 1 \rightarrow 4$ glycosidic bond. In contrast, the common GH70 GTF enzymes synthesize all four types of $\alpha$-glycosidic linkages possible. It appears unlikely that this is an intrinsic property of the non-sucrose utilizing type of GH70 enzymes. Therefore in the future $\alpha 1 \rightarrow 2$ and $\alpha 1 \rightarrow 3$ synthesizing non-sucrose utilizing type of GH70 enzymes may be found encoded by the ever increasing number of bacterial genome sequences, unless of course such synthetic capacities are not beneficial for the bacteria.

\section{The distinct reaction specificities of $4,6-\alpha$ GTs and GTFs}

Currently it is puzzling why 4,6- $\alpha$ GTs use maltooligosaccharides, but not sucrose, as glucose donor. Because GTFs cleave the glycosidic linkage between the glucosyl and fructosyl moieties of sucrose, and 4,6- $\alpha$ GTs the $\alpha 1 \rightarrow 4$ glycosidic linkage between two glucosyl moieties, structural differences are expected at substrate binding subsite +1 , which holds either a glucosyl or fructosyl unit (see Fig. 6 for subsite nomenclature). Whether the differences at subsite +1 (Table 1) are the only requirements to interchange the reaction specificities of GH70 enzymes or that additional mutations more remote from the catalytic center are required currently is unknown. In addition, acceptor subsite +2 has a few different amino acids (Table 1), which might contribute to the 4,6- $\alpha \mathrm{GT}$ reaction specificity. For GTFs, it is known that amino acid substitutions at subsite +1 (in position 1140) and subsite +2 (in positions 1137 and 1141) drastically alter the ratio of $\alpha$ glycosidic linkages in the $\alpha$-glucan polymers made by the enzymes (Shimamura et al. 1994; van Leeuwen et al. 2009). Further mutational analysis of the 4,6- $\alpha$ GT acceptor subsites thus may allow elucidation and modification of their glycosidic linkage specificity. 
Fig. 6 Schematic diagram of the reactions catalyzed by $4,6-$ $\alpha \mathrm{GT}$ enzymes. The open squares indicate the glucose moiety transferred by the enzyme. The sugar binding subsite nomenclature is according to Davies et al. (1997), in which the glycosidic bond is cleaved between donor subsite -1 and acceptor subsite +1

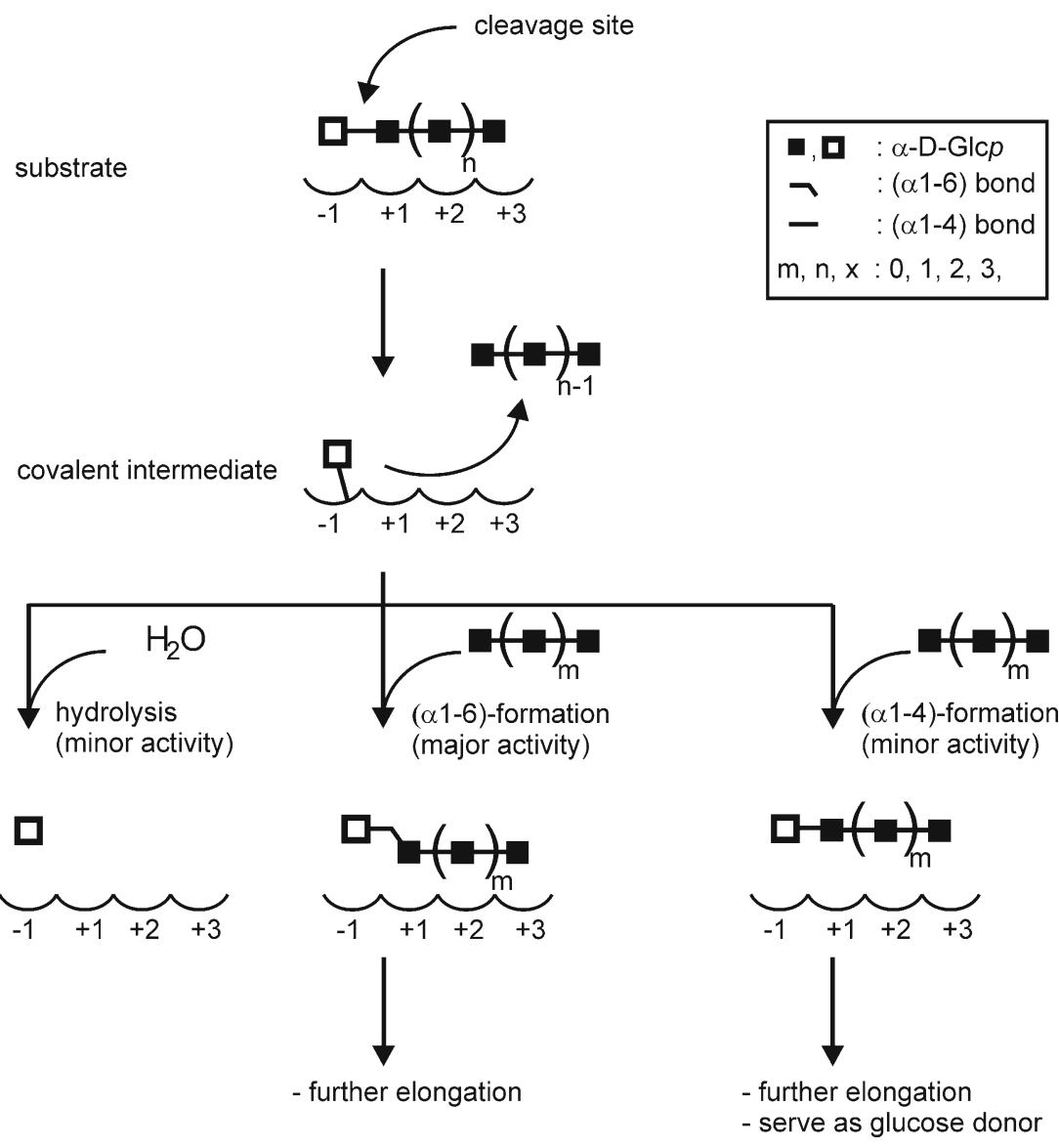

Another remarkable difference is that 4,6- $\alpha \mathrm{GTs}$ synthesize linear $\alpha$-glucans only, whereas GTFs often produce branched polymers. Since linear $\alpha$-glucans take up less space than branched ones, 4,6- $\alpha \mathrm{GT}$ s may possess a narrower acceptor binding cleft. In this regard, it is noteworthy that the loop connecting domains IV and B (residues 932-943 in GTF-180) is eight residues longer in 4,6- $\alpha$ GTs compared to GTFs (Fig. 1). The crystal structures of GTF-180 and GTF-SI (Vujičić-Žagar et al. 2010; Ito et al. 2011) show that part of this loop delineates the active site; a longer loop at this position thus may result in a more restricted binding cleft in 4,6$\alpha$ GTs. To further study this hypothesis, 3D structural information is needed, and currently, we are trying to obtain crystal structures of 4,6- $\alpha \mathrm{GT}$ proteins.

Differences and similarities with other $\alpha$-glucan acting enzymes

Furthermore, enzymes such as 4 - $\alpha$-glucanotransferase, cyclodextrin glucanotransferase, branching enzyme, and dextrin dextrinases disproportionate $(1 \rightarrow 4)-\alpha$-glucans (MacGregor et al. 2001; Cantarel et al. 2009; Zona et al. 2004; Palomo et al. 2011; Kelly et al. 2009a; Naessens et al. 2005). However, these GH13, 57, and 77 enzymes synthesize different products than 4,6- $\alpha$ GTs. Note that the sequences of dextrin dextrinases are unknown, as the genes have not been identified yet. Cyclodextrin glucanotransferases make cyclic $(1 \rightarrow 4)$ - $\alpha$-glucans (e.g., cyclodextrins), 4- $\alpha$-glucanotransferases cleave and synthesize $\alpha 1 \rightarrow 4$ glycosidic bonds thereby altering the $(1 \rightarrow 4)$ - $\alpha$-glucan chain distribution, and branching enzymes cleave $\alpha 1 \rightarrow 4$ glycosidic bonds and transfer the cleaved-off chain to a HO-6 group within a $(1 \rightarrow 4)$ - $\alpha$-glucan, yielding an $\alpha 1 \rightarrow 6$ branch. These enzymes cleave internal $\alpha 1 \rightarrow 4$ glycosidic linkages (i.e., endo-acting), whereas 4,6- $\alpha$ GTs are exo-acting enzymes that cleave off the non-reducing glucose unit from an $(1 \rightarrow 4)$ - $\alpha$-glucan chain.

Moreover, cyclodextrin glucanotransferases and 4- $\alpha$ glucanotransferases synthesize $\alpha 1 \rightarrow 4$ glycosidic bonds, whereas 4,6- $\alpha$ GTs make $\alpha 1 \rightarrow 6$ bonds. Although branching enzymes also form $\alpha 1 \rightarrow 6$ bonds, they create $\alpha 1 \rightarrow 6$ bonds in the middle of $\alpha$-glucan chains, resulting in branch points, whereas 4,6- $\alpha$ GTs attach the glucose unit via an $\alpha 1 \rightarrow 6$ glycosidic linkage to the non-reducing end of an $\alpha$-glucan chain yielding linear products.

The reaction specificity of dextran dextrinases comes closest to that of 4,6- $\alpha \mathrm{GTs}$, both transferring single glucose moieties from the non-reducing end of maltooligosaccharides to synthesize isomalto/maltooligosaccharides (Yamamoto et al. 
1993a; Kralj et al. 2011). The crucial difference between the two types of enzymes is that dextrin dextrinases form branched carbohydrates (Yamamoto et al. 1993b; Wang et al. 2011; Sims et al. 2001; Tsusaki et al. 2009). A second difference is that dextrin dextrinases disproportionate isomaltooligosaccharides (Yamamoto et al. 1993a), whereas isomaltooligosaccharides are not a substrate of $4,6-\alpha \mathrm{GTs}$. This is relevant as this means that dextran dextrinases can disproportionate their own reaction products, whereas 4,6$\alpha$ GTs cannot. A key question that remains to be answered is whether dextran dextrinases are evolutionary related to the GH70 enzymes. Based on their activity they combine the disproportionation activity of 4,6$\alpha \mathrm{GTs}$ and the branching activity of GH70 glucansucrases. The answer to this question requires the identification of the dextran dextrinase (gene) sequence.

A further difference is that GH70 enzymes, including 4,6- $\alpha$ GTs, are more hydrolytic than the GH13 and GH77 transglycosylases. For example, the $k_{\text {cat(transglycosylation) }} / k_{\text {cat }}$ (hydrolysis) ratio of the GH13 Neisseria polysaccharea amylosucrase is 20 (Albenne et al. 2004), that of GH13 Bacillus circulans CGTase is 90 (van der Veen et al. 2001), GH13 branching enzymes have ratios of $>>1,000$, and the GH77 4$\alpha$-glucanotransferases of Thermus thermophilus and $T$. brockianus have ratios of 5,000 (Kaper et al. 2007; Jung et al. 2011). GH70 GTFs, in contrast, are predominantly hydrolytic in the early phase of sucrose conversion, and they become transglycosylases when better acceptor substrates become available as result of the transglycosylation activity or when good acceptor substrates are added at the start of a reaction (Kralj et al. 2004b). Here, we find that also 4,6$\alpha$ GT-W has about $50 \%$ hydrolytic activity at the start of a reaction with low concentrations of linear $(1 \rightarrow 4)$ - $\alpha$-D-glucooligosaccharides and becomes a better transglycosylase once products appear that again function as acceptor substrate. The acceptor subsites of GH70 enzymes seem thus to be optimized for recognizing and utilizing the products made by the enzyme as acceptor substrates in a polymerization reaction.

\section{Applications and future perspectives of 4,6- $\alpha \mathrm{GTs}$}

4,6- $\alpha$ GTs are an exciting type of novel enzymes that convert $(1 \rightarrow 4)$ - $\alpha$-glucan substrates into linear $\alpha$-glucan products with a high percentage of $\alpha 1 \rightarrow 6$ glycosidic linkages (i.e., isomaltooligosaccharides built on maltooligosaccharides). These enzymes are potentially very useful for the synthesis of carbohydrate displaying compounds. Indeed, GH13 and GH70 enzymes are being used for the glycosylation of a variety of compounds (Desmet and Soetaert 2011; Leemhuis et al. 2010; Homann and Seibel 2009). The fact that 4,6$\alpha$ GTs synthesizes mainly $\alpha 1 \rightarrow 6$ glycosidic bonds ensures that the products are water-soluble, which is beneficial for increasing the solubility of poorly water-soluble compounds such as drug molecules.

Because 4,6- $\alpha$ GTs generate $\alpha$-glucans with a high degree of $\alpha 1 \rightarrow 6$ bonds, their products are water-soluble, which is advantageous for applications such as energy and soft drinks. The $\alpha 1 \rightarrow 6$ linkages, in addition, make the products resistant to $\alpha$-amylase digestion and the products as such are expected to pass the human stomach and small intestine and enter the colon were they can serve as carbon source for health promoting bacteria. Thus, 4,6- $\alpha$ GTs are expected to convert readily degradable maltooligosaccharides into a novel type of "resistant" $\alpha$-glucans and are thus potentially of great interest to the food industry (Dijkhuizen et al. 2011).

Acknowledgments This project is part-financed by the European Union, European Regional Development Fund and The Ministry of Economic Affairs, Agriculture and Innovation, Peaks in the Delta, the Municipality of Groningen, the Province of Groningen as well as the Dutch Carbohydrate Competence Center (CCC WP2c). Dr. Gerrit J. Gerwig for technical assistance with the methylation analysis, and Peter Sanders and Geralt ten Kate for the HPAEC analyses. We thank Professor Rolf Boelens (Bijvoet Center, Department of NMR Spectroscopy, Utrecht University, The Netherlands) for providing us with measuring time on the 500-MHz NMR instrument.

Open Access This article is distributed under the terms of the Creative Commons Attribution License which permits any use, distribution, and reproduction in any medium, provided the original author(s) and the source are credited.

\section{References}

Albenne C, Skov LK, Mirza O, Gajhede M, Feller G, D'Amico S, André $\mathrm{G}$, Potocki-Véronèse $\mathrm{G}$, van der Veen BA, Monsan $\mathrm{P}$, Remaud-Siméon M (2004) Molecular basis of the amylose-like polymer formation catalyzed by Neisseria polysaccharea amylosucrase. J Biol Chem 279:726-734

Bendtsen JD, Nielsen H, von Heijne G, Brunak S (2004) Improved prediction of signal peptides: SignalP 3.0. J Mol Biol 340:783795

Binder TP, Côté GL, Robyt JF (1983) Disproportionation reactions catalyzed by Leuconostoc and Streptococcus glucansucrases. Carbohydr Res 124:275-286

Brison Y, Pijning T, Malbert Y, Fabre E, Mourey L, Morel S, PotockiVéronèse $\mathrm{G}$, Monsan $\mathrm{P}$, Tranier $\mathrm{S}$, Remaud-Siméon $\mathrm{M}$, Dijkstra BW (2012) Functional and structural characterization of an $\alpha$ $(1 \rightarrow 2)$ branching sucrase derived from DSR-E glucansucrase. J Biol Chem. doi:10.1074/jbc.M111.305078

Cantarel BL, Coutinho PM, Rancurel C, Bernard T, Lombard V, Henrissat B (2009) The Carbohydrate-Active EnZymes database (CAZy): an expert resource for glycogenomics. Nucleic Acids Res 37:D233-D238

Ciucanu I, Kerek F (1984) A simple and rapid method for the permethylation of carbohydrates. Carbohydr Res 131:209-217

Côté GL, Robyt JF (1982) Isolation and partial characterization of an extracellular glucansucrase from Leuconostoc mesenteroides NRRL B-1355 that synthesizes an alternating $(1 \rightarrow 6),(1 \rightarrow 3)-\alpha$ D-glucan. Carbohydr Res 101:57-74 
Davies GJ, Wilson KS, Henrissat B (1997) Nomenclature for sugar-binding subsites in glycosyl hydrolases. Biochem $\mathrm{J}$ 321:557-559

Desmet T, Soetaert W (2011) Enzymatic glycosyl transfer: mechanisms and applications. Biocatal Biotransform 29:1-18

Dijkhuizen L, van der Maarel MJEC, Kamerling JP, Leemhuis H, Kralj S, Dobruchowska JM (2010) Gluco-oligosaccharides comprising $(\alpha 1-4)$ and ( $\alpha 1-6)$ glycosidic bonds, use thereof, and methods for providing them. $\mathrm{WO} / 2010 / 128859$

Dobruchowska JM, Gerwig GJ, Kralj S, Grijpstra P, Leemhuis H, Dijkhuizen L, Kamerling JP (2012) Structural characterization of linear isomalto/malto-oligomer products synthesized by the novel GTFB 4,6- $\alpha$-glucanotransferase enzyme from Lactobacillus reuteri 121. Glycobiology. doi:10.1093/glycob/cwr167

Domań-Pytka M, Bardowski J (2004) Pullulan degrading enzymes of bacterial origin. Crit Rev Microbiol 30:107-121

Fabre E, Bozonnet S, Arcache A, Willemot R-M, Vignon M, Monsan P, Remaud-Siméon M (2005) Role of the two catalytic domains of DSR-E dextransucrase and their involvement in the formation of highly $\alpha-1,2$ branched dextran. J Bacteriol 187:296-303

Goujon M, McWilliam H, Li W, Valentin F, Squizzato S, Paern J, Lopez R (2010) A new bioinformatics analysis tools framework at EMBL-EBI. Nucleic Acids Res 38:W695-W699

Hellmuth H, Wittrock S, Kralj S, Dijkhuizen L, Hofer B, Seibel J (2008) Engineering the glucansucrase GTFR enzyme reaction and glycosidic bond specificity: toward tailor-made polymer and oligosaccharide products. Biochemistry 47:6678-6684

Homann A, Seibel J (2009) Chemo-enzymatic synthesis and functional analysis of natural and modified glycostructures. Nat Prod Rep 26:1555-1571

Irague R, Massou S, Moulis C, Saurel O, Milon A, Monsan P, Remaud-Siméon M, Portais J-C, Potocki-Véronèse G (2011) NMR-based structural glycomics for high-throughput screening of carbohydrate-active enzyme specificity. Anal Chem 83:12021206

Ito K, Ito S, Shimamura T, Weyand S, Kawarasaki Y, Misaka T, Abe K, Kobayashi T, Cameron AD, Iwata S (2011) Crystal structure of glucansucrase from the dental caries pathogen Streptococcus mutans. J Mol Biol 408:177-186

Jung J-H, Jung T-Y, Seo D-H, Yoon S-M, Choi H-C, Park BC, Park CS, Woo E-J (2011) Structural and functional analysis of substrate recognition by the 250s loop in amylomaltase from Thermus brockianus. Proteins 79:633-644

Kaditzky SB, Behr J, Stocker A, Kaden P, Ganzle MG, Vogel RF (2008) Influence of $\mathrm{pH}$ on the formation of glucan by Lactobacillus reuteri TMW 1.106 exerting a protective function against extreme pH values. Food Biotechnol 22:398-418

Kaper T, Leemhuis H, Uitdehaag JCM, van der Veen BA, Dijkstra BW, van der Maarel MJEC, Dijkhuizen L (2007) Identification of acceptor substrate binding subsites +2 and +3 in the amylomaltase from Thermus thermophilus HB8. Biochemistry 46:5261-5269

Kelly RM, Dijkhuizen L, Leemhuis H (2009a) Starch and $\alpha$-glucan acting enzymes, modulating their properties by directed evolution. J Biotechnol 140:184-193

Kelly RM, Dijkhuizen L, Leemhuis H (2009b) The evolution of cyclodextrin glucanotransferase product specificity. Appl Microbiol Biotechnol 84:119-133

Kralj S, van Geel-Schutten GH, Rahaoui H, Leer RJ, Faber EJ, van der Maarel MJEC, Dijkhuizen L (2002) Molecular characterization of a novel glucosyltransferase from Lactobacillus reuteri strain 121 synthesizing a unique, highly branched glucan with $\alpha-(1 \rightarrow 4)$ and $\alpha-(1 \rightarrow 6)$ glucosidic bonds. Appl Environ Microbiol 68:42834291

Kralj S, van Geel-Schutten GH, Dondorff MMG, Kirsanovs S, van der Maarel MJEC, Dijkhuizen L (2004a) Glucan synthesis in the genus Lactobacillus: isolation and characterization of glucansucrase genes, enzymes and glucan products from six different strains. Microbiology 150:3681-3690

Kralj S, van Geel-Schutten GH, van der Maarel MJEC, Dijkhuizen L (2004b) Biochemical and molecular characterization of Lactobacillus reuteri 121 reuteransucrase. Microbiology 150:2099-2112

Kralj S, Grijpstra P, van Leeuwen SS, Leemhuis H, Dobruchowska JM, van der Kaaij RM, Malik A, Oetari A, Kamerling JP, Dijkhuizen L (2011) 4,6- $\alpha$-Glucanotransferase, a novel enzyme that structurally and functionally provides an evolutionary link between glycoside hydrolase enzyme families 13 and 70. Appl Environ Microbiol 77:8154-8163

Larkin MA, Blackshields G, Brown NP, Chenna R, McGettigan PA, McWilliam H, Valentin F, Wallace IM, Wilm A, Lopez R, Thompson JD, Gibson TJ, Higgins DG (2007) Clustal W and Clustal X version 2.0. Bioinformatics 23:2947-2948

Leemhuis H, Kelly RM, Dijkhuizen L (2010) Engineering of cyclodextrin glucanotransferases and the impact for biotechnological applications. Appl Microbiol Biotechnol 85:823-835

MacGregor EA, Janecek S, Svensson B (2001) Relationship of sequence and structure to specificity in the $\alpha$-amylase family of enzymes. Biochim Biophys Acta 1546:1-20

Monchois V, Willemot R-M, Monsan P (1999) Glucansucrases: mechanism of action and structure-function relationships. FEMS Microbiol Rev 23:131-151

Morita H, Toh H, Fukuda S, Horikawa H, Oshima K, Suzuki T, Murakami M, Hisamatsu S, Kato Y, Takizawa T, Fukuoka H, Yoshimura T, Itoh K, O'Sullivan DJ, McKay LL, Ohno H, Kikuchi J, Masaoka T, Hattori M (2008) Comparative genome analysis of Lactobacillus reuteri and Lactobacillus fermentum reveal a genomic island for reuterin and cobalamin production. DNA Res 15:151-161

Moulis C, Joucla G, Harrison D, Fabre E, Potocki-Veronese G, Monsan P, Remaud-Simeon M (2006) Understanding the polymerization mechanism of glycoside-hydrolase family 70 glucansucrases. J Biol Chem 281:31254-31267

Naessens M, Cerdobbel A, Soetaert W, Vandamme EJ (2005) Dextran dextrinase and dextran of Gluconobacter oxydans. J Ind Microbiol Biotechnol 32:323-334

Palomo M, Pijning T, Booiman T, Dobruchowska JM, van der Vlist J, Kralj S, Planas A, Loos K, Kamerling JP, Dijkstra BW, van der Maarel MJEC, Dijkhuizen L, Leemhuis H (2011) Thermus thermophilus glycoside hydrolase family 57 branching enzyme: crystal structure, mechanism of action, and products formed. J Biol Chem 286:3520-3530

Potocki de Montalk G, Remaud-Siméon M, Willemot R-M, Sarçabal P, Planchot V, Monsan P (2000) Amylosucrase from Neisseria polysaccharea: novel catalytic properties. FEBS Lett 471:219-223

Schwab C, Walter J, Tannock GW, Vogel RF, Gänzle MG (2007) Sucrose utilization and impact of sucrose on glycosyltransferase expression in Lactobacillus reuteri. Syst Appl Microbiol 30:433443

Shimamura A, Nakano YJ, Mukasa H, Kuramitsu HK (1994) Identification of amino acid residues in Streptococcus mutans glucosyltransferases influencing the structure of the glucan product. J Bacteriol 176:4845-4850

Sims IM, Thomson A, Hubl U, Larsen NG, Furneaux RH (2001) Characterisation of polysaccharides synthesised by Gluconobacter oxydans NCIMB 4943. Carbohydr Polym 45:285-292

Stam MR, Danchin EGJ, Rancurel C, Coutinho PM, Henrissat B (2006) Dividing the large glycoside hydrolase family 13 into subfamilies: towards improved functional annotations of $\alpha$ amylase-related proteins. Protein Eng Des Sel 19:555-562

Tsusaki K, Watanabe H, Nishimoto T, Yamamoto T, Kubota M, Chaen H, Fukuda S (2009) Structure of a novel highly branched $\alpha$ glucan enzymatically produced from maltodextrin. Carbohydr Res 344:2151-2156 
van der Veen BA, Leemhuis H, Kralj S, Uitdehaag JCM, Dijkstra BW, Dijkhuizen L (2001) Hydrophobic amino acid residues in the acceptor binding site are main determinants for reaction mechanism and specificity of cyclodextrin-glycosyltransferase. J Biol Chem 276:44557-44562

van Hijum SAFT, Kralj S, Ozimek LK, Dijkhuizen L, van GeelSchutten IGH (2006) Structure-function relationships of glucansucrase and fructansucrase enzymes from lactic acid bacteria. Microbiol Mol Biol Rev 70:157-176

van Leeuwen SS, Kralj S, van Geel-Schutten IH, Gerwig GJ, Dijkhuizen L, Kamerling JP (2008a) Structural analysis of the $\alpha$-D-glucan (EPS35-5) produced by the Lactobacillus reuteri strain 35-5 glucansucrase GTFA enzyme. Carbohydr Res 343:1251-1265

van Leeuwen SS, Leeflang BR, Gerwig GJ, Kamerling JP (2008b) Development of a ${ }^{1} \mathrm{H}$ NMR structural-reporter-group concept for the primary structural characterisation of $\alpha$-D-glucans. Carbohydr Res 343:1114-1119

van Leeuwen SS, Kralj S, Eeuwema W, Gerwig GJ, Dijkhuizen L, Kamerling JP (2009) Structural characterization of bioengineered $\alpha$-D-glucans produced by mutant glucansucrase GTF180 enzymes of Lactobacillus reuteri strain 180. Biomacromolecules 10:580 588
Vujičić-Žagar A, Pijning T, Kralj S, López CA, Eeuwema W, Dijkhuizen L, Dijkstra BW (2010) Crystal structure of a 117 kDa glucansucrase fragment provides insight into evolution and product specificity of GH70 enzymes. Proc Natl Acad Sci USA 107:21406-21411

Walter J, Schwab C, Loach DM, Gänzle MG, Tannock GW (2008) Glucosyltransferase A (GtfA) and inulosucrase (Inu) of Lactobacillus reuteri TMW1.106 contribute to cell aggregation, in vitro biofilm formation, and colonization of the mouse gastrointestinal tract. Microbiology 154:72-80

Wang S, Mao X, Wang H, Lin J, Li F, Wei D (2011) Characterization of a novel dextran produced by Gluconobacter oxydans DSM 2003. Appl Microbiol Biotechnol 91:287-294

Yamamoto K, Yoshikawa K, Okada S (1993a) Detailed action mechanism of dextrin dextranase from Acetobacter capsulatus ATCC 11894. Biosci Biotechnol Biochem 57:47-50

Yamamoto K, Yoshikawa K, Okada S (1993b) Structure of dextran synthesized by dextrin dextranase from Acetobacter capsulatus ATCC 11894. Biosci Biotechnol Biochem 57:1450-1453

Zona R, Chang-Pi-Hin F, O'Donohue MJ, Janeček S (2004) Bioinformatics of the glycoside hydrolase family 57 and identification of catalytic residues in amylopullulanase from Thermococcus hydrothermalis. Eur J Biochem 271:2863-2872 